\title{
The International Health Regulations (2005): State of Implementation in Côte D'Ivoire in 2011
}

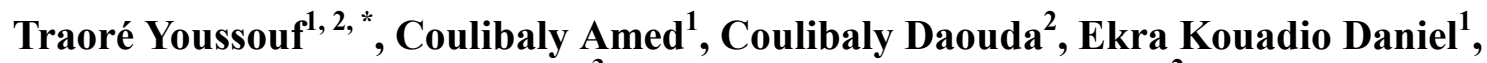 \\ N'Guessan Kouakou Christophe ${ }^{3}$, Koutouan Mayet Guy Georges ${ }^{2}$, Agbo Kouadio Serge ${ }^{4}$, \\ Dagnan N'Cho Simplice ${ }^{1}$ \\ ${ }^{1}$ Department of Public Health and Biostatistics, Faculty of Medical Sciences, University Félix Houphouët-Boigny (UFHB), Abidjan, Côte \\ d'Ivoire \\ ${ }^{2}$ Department of Epidemiological Surveillance, National Institute of Public Health, Abidjan, Côte d'Ivoire \\ ${ }^{3}$ Global Health Security Agenda, Centers for Disease Control and Prevention U.S. Abidjan Embassy, Abidjan, Cote d'Ivoire \\ ${ }^{4}$ Department of Preparedness and Response Project, Development Alternative Inc (DAI), United States Agency for International \\ Development, Abidjan, Cote d'Ivoire
}

Email address:

Traore_youl@yahoo.fr(T. Youssouf)

${ }^{*}$ Corresponding author

\section{To cite this article:}

Traoré Youssouf, Coulibaly Amed, Coulibaly Daouda, Ekra Kouadio Daniel, N’Guessan Kouakou Christophe, Koutouan Mayet Guy Georges, Agbo Kouadio Serge, Dagnan N'Cho Simplice. The International Health Regulations (2005): State of Implementation in Côte D'Ivoire in 2011. Science Journal of Public Health. Vol. 6, No. 3, 2018, pp. 66-74. doi: 10.11648/j.sjph.20180603.11

Received: February 25, 2018; Accepted: March 24, 2018; Published: April 12, 2018

\begin{abstract}
Côte d'Ivoire has decided to implement the International Health Regulations (IHR) (2005), which came into effect in June 2007. However, after a period of 5 years without the actual start, several observations have found deficiencies in the application of this legal instrument binding law. In collaboration with the World Health Organization (WHO), actions have been undertaken for its implementation. The purpose of this work was to assess the key minimum core capabilities required to prevent, detect early and respond to public health emergencies. A documentary review on the table took place from 01 to 09 December 2011 at the National Institute of Public Hygiene with all the sectors involved in the implementation of the IHR (2005). For this purpose following a sampling for convenience, An interview grouped by sub-themes made it possible to collect information from the questionnaire developed by WHO. The data collected was analyzed by highlighting the Strengths, Weaknesses, Opportunities and Threats (SWOT) of the 13 components of the IHR. Confidentiality and anonymity have been respected in order to accelerate the implementation of the capacities of this Regulation. In this study with 51 sectors involved, the minimum required such as legislation, coordination and National Focal Point (NFP) communication represented respectively 50\%,73\% and 57\% regarding the entities rate of involvement in the implementation of the IHR. Human resources and monitoring were not developed $(0 \%)$ unlike the laboratories $(90 \%)$, the response to events represented ( $85 \%)$. In addition, other aspects are in the early stages of implementation to various degrees. The assessment of strengths, weaknesses, opportunities and threats revealed significant progress in some technical areas (preparedness, response) and many insufficiencies in the implementation of the IHR (2005). All this shows the degree of involvement of entities in the implementation of the IHR in Côte d'Ivoire. IHR implementation is an investment to ensure the safety and health of global and Ivorian populations.
\end{abstract}

Keywords: Implementation, International Health Regulations, Côte d'Ivoire, 2011 


\section{Introduction}

Today's highly mobile, interdependent and interconnected world offers an array of opportunities for the rapid spread of infectious diseases. In response to these threats, the World Health Organization (WHO) recommends that states declare any event that may constitute a public health emergency of international concern. Because these events can, especially if global health security is not ensured, have repercussions on economic or political stability, trade, tourism, access to goods and services, and even if occur periodically, jeopardizing demographic stability [1]. To meet this need, the International Health Regulations (IHR) has been put in place to prevent and control the international spread of diseases, to protect people from diseases and to respond by a public health action that is proportionate and limited to public health risks, thus avoiding unnecessary barriers to international traffic and trade [2].

The first IHR adopted in 1951 and revised in 1969 required all WHO member states to report any cases of cholera, plague, or yellow fever that occurs within their borders [3, 4]. Then from 2005, after 10 years of discussion and debate the RSI was adopted (2005) [5] which laid out provisions and procedures that allow the international community to act in case of a risk or a Public Health Emergency of International scope (USPPI), whether natural, accidental or deliberate, biochemical or radioactive accidents [2].

Entered into force on 15 June 2007, States should establish the minimum capabilities required for the implementation of the International Health Regulations (2005). Unfortunately, some Member States, including Côte d'Ivoire, until November 2011, had not yet assessed the capability of existing national entities and resources and had a 2-year period from June 2012 to fulfill obligations of the capability titles by invoking a justified need from WHO.

It is to meet this obligation that the Ministry of Health and the Fight against AIDS through the National Institute of Public Hygiene (INHP) with the support of WHO, has set itself the goal of assessing the main capabilities required by the IHR (2005) to accelerate its implementation in Côte d'Ivoire. Its specific objectives were (i) to identify the level of involvement of the entities participating in the implementation of the IHR; (ii) to describe the activities carried out under the IHR; (iii) identify the Strengths, Weaknesses, Opportunities and Threats of implementing the IHR.

\section{Material and Methods}

\subsection{Study's Framework}

The National institute of public hygiene (INHP) is a national public establishment of administrative nature created by decree $\mathrm{N}^{\circ}$ 91-656 of 09 October 1991 and is the assigned National focal point by reference designation Letter
$\mathrm{N}^{\circ}: 6090 / \mathrm{MSHP} / \mathrm{INHP}-2007 / \mathrm{OKP}-\mathrm{RB}$ of 14 November 2007. It is in charge of the execution of the national health policy in matters of hygiene.

\subsection{Type of Study and Duration}

It was a descriptive cross-sectional study conducted with 51 entities involved in the implementation of the IHR (2005). It consisted of a desk review. This study took place from 01 to 09 December 2011.

\subsection{Sampling}

For the study, convenience sampling was the chosen method. There were 51 institutions that took part in the daily IHR activities (2005). The ministries involved were first identified and an invitation was sent to them. The responding unit was put in charge of implementing the IHR by the ministry in each entity.

\subsection{Data Collection}

The review provided a data collection that reflected the implementation of the IHR. Several documents have been used and representatives of the ministries or departments involved have been invited to facilitate and assist in providing basic information.

The qualitative approach consisted of creating working groups to gather information after the exchanges or focus groups with department heads or ministries involved in the implementation of IHR regulations (2005). To facilitate this interview, the main capabilities that had similarities were grouped into 5 thematicsubgroups. The participants were divided into the subgroups according to the entity they belong to. Some participants have, at their request, integrated other thematicsubgroups to contribute to this desk review's completion.

The interviews were conducted with the help of a guide that laid out different focuses of discussion according to the profiles of the representatives (people who are working in a field or who participated in an activity of the IHR) from the invited entities. For a week, the data collected daily was saved.

\subsection{Studied Variables}

These variables were related to the 13 main national capabilities required for the implementation of the IHR: National legislation, policy and finances; coordination and communication of the NFP; surveillance, action; preparedness; risk communication; human resources; laboratory services; human health's risks of zoonotic, dietary, chemical and radiological origin; and designated entry Points.

\subsection{Data Analysis}

To measure progress in building core capacities, a thematic area analysis was conducted using the SWOT (Strengths- 
Weaknesses-Opportunities-Threats) approach. The collected and compiled data were sent to the WHO Regional Office for analysis using an analytical program developed by WHO. At this level, each of these capabilities with multiple components should be analyzed.

\subsection{Confidentiality and Anonymity}

Confidentiality and anonymity were respected because it was a question of providing true information in order to accelerate the implementation of the main capabilities of the IHR (2005) in the country.

\section{Results}

This study analyzed the strengths, weaknesses, threats and opportunities (SWOT) of the various technical domains of the RSI (2005) in 51 sectors involved in its implementation. To this end, the threats observed ranged from nothingness, institutional and socio-political instability, from stopping to non-financing of projects across all the technical fields analyzed.

\subsection{Analysis of Strengths, Weaknesses, Opportunities and Threats (SWOT)}

The main strengths, weaknesses, opportunities and threats identified for each the activities taking into account the provisions of the IHR (2005) were as follows:

\subsubsection{Coordination et Communications at the National Focal Point (NFP) of IHR}

At this level, as forces there were the existence of a national anti-epidemic committee and coordination and communication mechanisms at the level of certain ministries, these mechanisms have been tested during certain crises (bird flu, milk contaminated with melanin).

Then the weaknesses identified were the insufficient awareness of IHR activities with relevant entities and sectors, extension of the IHR to relevant entities / sectors and the lack of in-depth evaluation of national legislation to align it with the provisions of the IHR.

Then the opportunities identified were the existence of texts that can promote the implementation of the IHR, stakeholders and authorities were motivated and an organization already exists at the level of each stakeholder.

Finally the threat was the existence of institutional instability.

\subsubsection{Surveillance}

In this technical area, the strengths were the results of the surveillance were actually communicated through the weekly electronic epidemiological survey called le Vigile (The watchman), standard operating procedures and guidelines for noticing, confirming, verifying, evaluating and reporting events have been implemented and Community leaders, networks, health volunteers and other members of the community were sensitized and actively involved in the detection and reporting of unusual health events.
In addition to these forces, the lack of an updated list of diseases / events under the IHR and non-updating of the national integrated disease surveillance plan and response were the weaknesses found.

The only opportunity was financing activities after registration in the Public Investment Plan (PIP).

\subsubsection{Response}

Strengths have been identified namely resources for rapid action in national or international public health emergencies were available and rapid response teams were available to deal with events that could constitute a public health emergency.

Weaknesses, on the other hand the irregularity in the functioning of the national committee for the fight against epidemics (CNLE), the non-inclusion of some fields in the rapid intervention team (Ministries or National Laboratory of Public Health), the insufficiency of standard operating procedures for certain events (radiological, chemical) and insufficient systematic evaluation of interventions. There were lack of focal points responsible for infection control, of policy and operational plan for infection control, of standard operating procedures for the control of infection (except for HIV / AIDS, Influenza) and of surveillance system for risk groups (Personnel).

The main opportunity was funding sources of financial technical partners.

\subsubsection{Preparedness}

The national plan of action in the event of a public health emergency was tested as part of simulation exercises (Félix Houphouët-Boigny International Airport) and updated.

However, in terms of weaknesses, there were the lack of mapping of structures, national resources involved in preparedness, of mapping and profile of public health risks, of an integrated national plan for epidemic preparedness and other public health emergencies, of assessment of the capacity of national entities and resources and finally of a list of experts in the field of epidemic and event management.

In additional, there were the absence of a roster of experts that can be mobilized in real time in the event of a public health emergency and the national action plan, in case of a public health emergency, did not include all events from the IHR (non-infectious risks);

\subsubsection{Risk Communication}

The results in terms of strengths were the presence of qualified resource persons in the field of communication, of information, education and communication media adapted to the populations, accessible and appropriate in the context of epidemics, of a risk communication training program at the regional IHR level and of a website within the focal point entity.

Concerning weaknesses, the lack of communication plan for risk management, of IHR menus and links to other sectors in the INHP website and the insufficient trained risk communication staff in relevant sectors. There was failure to respect the 24-hour deadline for informing partners and 
populations of the presence of a national or international public health risk

The willingness of the partners to support the permanent reflection framework on risk communication at the national focal point of IHR level and of the political authorities to support the implementation of the IHR and the presence of a favorable legal framework were the opportunities;

\subsubsection{Human Resources}

For these identified strengths, a unit of capacity development in terms of human resources and human resource development and training plan $t$ that takes into account the human resources requirements of the IHR were developed.

The lack of a needs assessment to identify limitations in national resources and training related to the IHR, the national human resources development plan or training action plan taking into account the requirements of the IHR is still being implemented and budgets allocated for training human resources for IHR risks were not available.

The presence of partner support for training and capacity strengthening in human resources was the opportunity without any threat.

\subsubsection{Laboratory Services}

The many strengths observed were the existence of decrees and orders, guides and directives, networks of international laboratories, a large number of samples collected by the National Reference centers, an external quality evaluation system, capacity to perform molecular biology techniques and local expertise in biological or chemical diagnosis of events.

While the lack of a national laboratory network, accredited laboratories according to international standards, diagnostic capability of peripheral laboratories at the level of the departmental directions of health, application of the directives on safety and biosecurity and non-involvement of peripheral laboratory staff in surveillance activities were the weaknesses.

Support from technical and financial partners was a favorable opportunity for the analysis of the levies

\subsubsection{Potential Risks}

\section{a. Events Related to Zoonoses}

The establishment of the national committee for the fight against avian influenza and the development of a National Plan for the fight against Avian Influenza existed,

However the only weakness listed was insufficient coordination of national programs.

There was an opportunity that was support from the United Nations Fund for Agriculture and the likely and probable threat was the presence of natural disasters (destruction of fauna and flora)

\section{b. Food Safety}

For this component, several strengths have been revealed namely the existence of standards and services responsible for controlling dietary risk, food control laboratories (national public health laboratory, Codinorm), a list of priority risks for food safety, a health safety control and management system and laws and regulations related to food safety.

Weaknesses were lack of an operational food safety coordination mechanism and information on the INFOSAN network, surveillance guidelines and management of health risks.

Opportunities were support of Codex Alimentarus: International multisectoral platform which discusses food standards and the United Nations fund for agriculture, the world food program and hellen killer international support the national nutrition program coordinating department for the revision of standards.

c. Chemical Events

Many efforts have been made in this sector, and it has emerged that the policies and plans for monitoring, alerting and responding to a chemical incident and a laboratory service for the confirmation of certain priority chemical events existed and the one hand that an emergency response plan defining the roles and responsibilities of organizations in chemical emergencies and also monitoring for chemical events on the other hand was existed.

In addition to the experiences were acquired and visible observations concerning certain events and chemical risks communicated to the international community.

However, the weaknesses were the shortcomings in national policies or plans for monitoring, warning and response to chemical incidents, lack of training staff and materials for the management of chemical events, national guidelines for managing the transport of biological samples and chemical wastes and coordination mechanisms with other relevant sectors.

There were also lack of a monitoring system, manuals and standard operating procedures related to urgent chemical events and potential chemical hazards, response capabilities in the event of a chemical event; and the absence of poison control centers.

The opportunity was the presence of partnerships with international organizations for capacity building (materials, training and equipment) and like Threat, it had been found the existence of disasters related to chemical weapons.

d. Emergencies Linked to Ionizing Radiation

As regards the strengths noted for this technical area, the structures existed the ionizing radiation protection subdirectorate of the national public health laboratory (LNSP), the national office of civil protection and materials for the detection, recovery and packaging of orphan strains through the GTRI project (United states department of energy).

Then the Weaknesses were the lack of national policies or plans for the detection and management of radiation emergencies, training personnel and equipment for emergencies, national guidelines for managing the transport of biological samples and radioactive waste, coordination mechanisms between the competent national authorities and other sectors.

A monitoring system and guidelines for the reporting and assessment of ionizing radiation events, collaboration with 
other specialized laboratories and emergency response capabilities were absent.

Finally the failure of alpha, beta and gamma spectrometers to identify radioelements was identified;

The opportunities that existed were technical cooperation relations with the international atomic energy agency (IAEA) through which there is provision of equipment, technical assistance through expert missions.

\subsubsection{Entry Points}

At the point of entry, availability and transmission of a list of designated Entry Points to WHO (Noé, pogo, laleraba), regulatory acts relating to activities at ports of entry and a contingency plan tested for pandemics at Félix HouphouëtBoigny international airport were noted. To those there, added the fact that a few points of entry able to subject travelers to sanitary controls of entry and exit of travelers (Noé, sitarail, pogo, laleraba), provisional quarantine pandemic cells at the Félix Houphouët-Boigny International Airport and finally had appropriate equipment and trained personnel at the airport, port and Noah border post.

Apart from these noted strengths, the weaknesses identified have shown that the 3 designated border posts (Noé, pogo, laleraba) were non-functional. Then communication between staff (security and health) at entry points, surveillance of bacteriological, nuclear and chemical hazards, filtering and case management at points of entry (entry and exit) and vector control program at entry points were insufficient.

The recognized Ivorian experience in managing pandemics at the airport was a real opportunity.

\subsection{Level of Development of the Main Capabilities of the IHR (2005) in Côte d'Ivoire}

Capabilities such as NFP legislation, coordination and communication accounted for $50 \% ; 73 \%$ and $57 \%$ respectively in all entities involved in this implementation of the IHR. Capabilities for human resources and surveillance were not developed (0\%), unlike laboratories (90\%); the response to events accounted for $(85 \%)$. In addition, other aspects are in the early stages of implementation to various degrees. (Figure 1)

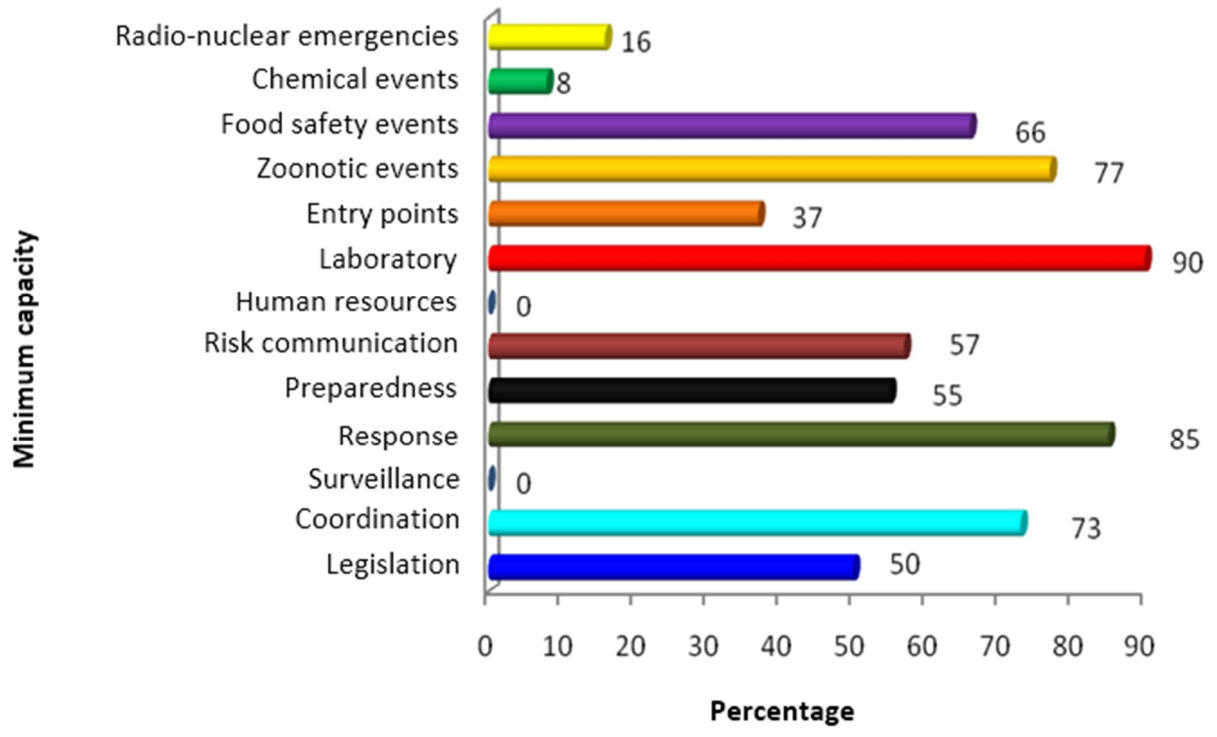

Figure 1. Minimum implementation capacities in Côte d'Ivoire in 2011.

\section{Discussion}

The encountered difficulties were with regard to access to all the entities involved with the IHR. All these constraints have had a negative impact on the evaluation process in terms of time and the effective filling of the questionnaire. Scheduled visits at the entry points for this purpose couldn't be conducted to further refine the analysis and recommendations. One of the limitations is that the SWOT analysis conducted, did not allow to find the components of the various capabilities to better refine the comments.

\subsection{Legislation, Coordination and Communication of the National Focal Point (NFP)}

In Côte d'Ivoire, the establishment of a national legislation policy regarding the IHR's (2005) provisions is important in order to better contain epidemics or pandemics. This capability was carried out in half $(50 \%)$ by the entities in charge of the IHR which enforce the legal provisions. This is different from the Republic of Niger and in Taïwan, where the political and administrative authorities have legislated on the subject, thus giving a strength and a legal character to the legal provisions of this international agreement. This is also the case in a study conducted by Liu B and col in Hong Kong, China since the advent of SARS, influenza A H1N1, avian flu, and other epidemics, which has changed the landscape at the national level. of International Health Security the National Committee for Nuclear Accident Coordination and the former Food Security office of the State Council jointly established and improved the coordination 
mechanism [8, 23, 24]. National legislation in Côte d'Ivoire needs to be revised in order to facilitate the attainment of this capability as many difficulties are encountered in the implementation of the IHR. During their study on the IHR in Uganda, Wamala et al [13] recommended revising the national legislation.

This remark was also made to the Moroccan authorities in the study conducted by Saloua A [14] who reported that there was a delay in updating the Moroccan legislation and regulations of the RSI. The national political will in favor of international health security is an asset for the implementation of the provisions of the IHR (2005).

Given its central role the National IHR Focal Point must help in coordinating with other relevant national sectors to communicate and broadcast public health events of international concern, National IHR Focal Points must play a vital role in coordinating relevant national sectors. In Côte d'Ivoire, it turns out that coordination and communication are carried out but often with difficulties. Indeed, many countries in the African Region and many others did not have the means to communicate regularly with relevant sectors or to notify WHO of potential public health emergencies [7].

Member States often did not report public health events within twenty-four hours, as recommended by the IHR, for fear of economic consequences. This results in delays in the implementation of adequate responses to prevent the possible national and international spread of these events [7].

\subsection{Risk Communication}

The Ministry of Health and the fight against AIDS through its technical structure has a website and a communication system for the dissemination of messages and information related to PHEICs. Risk communication is an integral part of the management of public health emergencies. This website was sometimes accessible to the public for the dissemination of information, but it was not updated regularly and had huge problems that made it hard to use. In a study on the evaluation of the implementation of the IHR (2005) in Uganda in 2009 the same findings (57\%) were noted [13].

In this study, it emerged that risk communication plans were not written by all WHO Member States during epidemic seasons but were only available at the beginning of outbreaks. Proactive communication encourages people to adopt protective behaviors, facilitates increased disease surveillance, reduces confusion and allows better use of resources.

\subsection{Surveillance, Response and Preparedness}

Despite the revision of the guide for Integrated Disease Surveillance and Response (IDSR), several African countries face enormous difficulties in implementing the IHR. Côte d'Ivoire is among the countries that have not developed all the components of this surveillance capacity $(0 \%)$. This has resulted in shortcomings in the collection, analysis, systematic interpretation of data, and especially in the reporting of public health events of international concern, as recommended by the IHR (2005) [7].

The IHR (2005) mandated all Member States, in its Article 5 , to develop and maintain the capacity to detect, monitor, report all public health events [12] but the results was different from those recommended by WHO because most of these points were not taken into account; it was the same case described by Wamala JF et al [13] in their study where he stated that Uganda had not yet updated its surveillance tools, guidelines, disease case definition and integrated potential risks related to events (chemical, radionuclear). Nevertheless, thanks to avian influenza, sentinel sites [19] have been installed in poultry production and breeding areas all over the country. The absence of notification caused delays in the implementation of adequate interventions to prevent the possible national and international spread of these events [7].

In Article 13 of the IHR (2005), Member States are requested to develop, strengthen and maintain the capacity to quickly respond and effectively to public health risks and health emergencies of international concern as stated in the Annex. 1 of the Regulation [12]. Standard Operating Procedures (SOPs), guides and guidelines for the prevention of certain diseases have been drafted but virtually nonexistent for chemical and radionuclear events, as stated in Uganda by the study by Wamala et al [13]. On the other hand, responses (care, investigations) were made during the dumping of toxic waste in Abidjan in 2006, the pandemic influenza (H1N1).

Preparedness plans existed for most of the diseases under surveillance. For example, an action plan to prevent the spread of communicable diseases by air travelers at Félix HOUPHOUET-BOIGNY International Airport was drafted in favor of influenza (H1N1) 2009 [15]. In addition, the plans were absent for potential risks (chemical) and for the list of experts in all these areas, except the radiological or nuclear field. Reactive and preventive mass vaccination campaigns were carried out following epidemics or to cope with them, for example, the preventive vaccination campaign in districts at risk of yellow fever epidemic in Côte d'Ivoire in 2011 and 2012 [16].

\subsection{Potential Risks Related to Events}

Member States in the WHO African Region did not yet have sufficient laboratory capacity to diagnose chemical, biological and radionuclear events. This was the same in Côte d'Ivoire where capacity for chemical events and radio nuclear emergencies was below $20 \%$.

In contrast to Uganda's study by Wamala JF et al [13] that showed that laboratory diagnostic capabilities were enhanced with the exception of radionuclear. Laboratory capacity was particularly weak at subnational and health district levels, resulting in delays in the confirmation and monitoring of public health events presenting a risk of international spread [7]. 


\subsection{Entry Points}

The IHR (2005) recommends that all signatories to the international agreement identify entry points, including at designated airports, ports and designated border posts and RSI requires States parties to develop core capacities to detect, assess, report and respond to international concern potential public and health emergencies by respecting key capabilities to control and contain the disease at points of entry $[10,22]$. Contrary to the point made by the WHO at its 58th Word Health Assembly (WHA) the entry points work in the Côte d'Ivoire (37\%) except for the Felix HouphouetBoigny international airport wich serves as a place of internship for countries in the African region. As a matter of fact, at the last WHO meeting in December 2013 in Yaoundé (Cameroon), the country's representatives made a solemn declaration to help assist other States in the implementation of the IHR. With regard to the ports (02) of Abidjan and SanPedro, the implementation of the IHR was going well because several provisions of the new IHR have been taken into account but the fact remains that difficulties were encountered (circulation of the surveillance team, administrative slowness). So, the challenge remains at the three designated border posts (03) because the land borders are very permeable and wide making it difficult to control health. According to WHO's findings, most of the Member States of the WHO african region [7] did not have designated entry points in their territories, have not applied procedures for sanitary inspection of vessels and have and neither adopted the new health control certificate. The results described were identical to those of the study conducted in Tanzania by Bakari and Florence because the airport lacked an isolation room for observation in case of public health events [21]. In addition, entry points service personnel of health and others were often untrained or retrained and generally lack the equipment and infrastructure to detect, report public health events, and set up a response. [7, 13, 21]. Moreover, China and Taiwan, inspection and quarantine capabilities, health monitoring, surveillance and control of the media, monitoring and control of nuclear, biological and chemical factors, and laboratory capacity has been improved $[23,24]$.

\subsection{Human Resources}

Regarding the capability for human resources, the development and capacity strengthening plans were drafted but the accompanying measures were not followed to the point that the project did not start. The results $(0 \%)$ differ from those produced by the WHO african region [7].

The effective implementation of the IHR components and its appropriation by the competent authorities will fix these shortcomings. On the other hand, some training activities were taken into account by financial technical partners. In short, this capability remains a key component in the implementation of IHR in our countries and we must face many challenges.

In the report entitled International Health Security in the twenty-first century [8], some countries had more difficulty coping with the threats to health security because their health infrastructure collapsed as a result of lack of investments and the shortage of trained health personnel, or because this infrastructure has been damaged or destroyed by armed conflict or a previous natural disaster.

\subsection{Laboratory Services}

The prevention of infectious and noncommunicable diseases requires accurate diagnostic information. The critical importance of high quality laboratory services is now widely recognized.

These laboratories play key roles in the implementation of the International Health Regulations (2005) nationally and internationally because they are the elements of surveillance, alert, diagnostic confirmation and orientation of care or decision. They partly comply with the new provisions recommended by WHO. The results were sharply increasing $(90 \%)$ unlike in previous years because since the advent of pandemic influenza (H1N1) in June 2009, the laboratory has become the National reference center influenza (CNR) giving it several potentialities for diagnostic and research. Other labs brought their expertise to confirm or deny events. However, there are mechanisms for transporting samples according to the pathologies under surveillance. For example, sentinel influenza surveillance sites have a system for storing, collecting and delivering samples. WHO in its report of the 58th WHA showed the difficulties encountered by several member states of the African region in the management of samples collected, the quality of human resources and laboratories and finally the availability of inputs and outputs $[7,9,11,21]$.

To meet international requirements, countries must demonstrate political determination and be able to take the necessary development and compliance measures to provide accurate and reliable laboratory results in a timely fashion, those conditions are necessary for activities in the field of health and for international health security [20].

Studies by Masanza and al $[17,18]$ showed that little effort has been made to help laboratories achieve international standards (ISO 15189) and move towards accreditation. On the other hand, Liu B et al, during their work in China reported that the network of laboratory tests for public health emergencies has been established [23].

However, there was little or no distribution of available national laboratory guidelines and a lack of internal and external quality insurance systems, which is usually accompanied by a low quality control assessment. In a study conducted in the Caribbean [19], it was also found that few WHO member countries did not have a National Public Health Laboratory.

\subsection{Capabilities Regarding Zoonotic Risks and Ionizing Radiation}

The zoonotic events were monitored and reported as seen during the 2006 outbreak of the bird flu epidemic in our 
country. This has resulted in a perfect collaboration between epidemiologists and veterinarians in managing this crisis. And even in 2009, several activities were carried by the actors involved. The Results (77\%) were similar to those of WHO Afro (70\%) in 2012 [11].

Emergency management related to ionizing radiation and chemical events have improved due to the supply of equipment (reagents) and the strengthening of qualified personnel's capacity. This has been demonstrated in the aftermath of the spills of toxic waste in the port with its procession of patients, deaths and after-effects on the populations where radioactive dosages and controls were carried out. This evaluation even showed at the regional level the places of interest for the two (02) events. Though, several cases of poisoning or death investigated in the territory remain unresolved because the laboratories concerned are not equipped.

\section{Conclusion}

The assessment of the implementation of the International Health Regulations (2005) in Côte d'Ivoire is encouraging, three years from the deadline. However, efforts must be made at all levels and by all actors to achieve meaningful results in order to face all threats or public health emergencies regardless of origin.

The health system partially meets the requirements of the IHR (2005) at all capability levels. However, shortcomings or deficiencies were found in the 13 main capacities. Emphasis must be placed on these imperfections in order to comply with the provisions of the IHR (2005) because crisis management cannot be improvised. It takes a minimum of preparation to deal with eventualities that may arise.

\section{References}

[1] Hubert B. The implementation of the new International Health Regulations as part of border control at Lyon Saint-Exupéry International Airport. Memory 2007-2008. 103p.

[2] World Health Organization (WHO). Règlement sanitaire international (2005). Genève 2006. 1-78.

[3] World Health Organization (WHO). Frequently asked questions about the RSI. Resolution WHA 58.3; [Internet]. Available on: www.who.int/csr/howtheywork/faq/fr/.

[4] World Health Organization (WHO). The International Health Regulations (2005): Information Note RSI. A58 / 4. May 16, 2005. 1-65.

[5] World Health Organization (WHO). Representative Office in Morocco. Morocco, its commitments to improve healthrelated safety: Reduce risks to national public health through the International Health Regulations. World Health Day 2007. Morocco; Apr 2, 2007.

[6] Assemblée Mondiale de la Santé (AMS). Révision du Règlement Sanitaire International. Résolution WHA 58.3. 23 Mai 2005.
[7] World Health Organization (WHO). Regional Office for Africa. Application of the International Health Regulations (2005) in the WHO African Region.

[8] World Health Organization (WHO). International Health Security "Investing in Health, Building a Secure Future". World Health Day 2007. World Health Organization (WHO). Application of the IHR (2005). WHA. 3 (59): 1-5.

[9] World Health Organization (WHO). Points of entry under the IHR (2005). IHR Brief No. 3. Available from: http://www.who.int/ihr/publications/ihr_brief_no_3_en.pdf [cited 23 April 2014].

[10] Axelle A. Ebode Ebene. International Health Regulations (2005) and Global Health Security: From International Issues to Local Perspectives. Case of Nine African Countries with a Pasteur Institute. MGR 2008-2009. Jan 2010: 1-166.

[11] World Health Organization WHA. Revision of the International Health Regulations. WHA [Internet]. 2005; 3 (58). Availableat: http://www.who.int/gb/ebwha/pdf_files/WHA58REC1/english/Resolutions.pdf13.

[12] Wamala et al. Assessment of core capacities for the International Health Regulations (IHR [2005]) - Uganda, 2009. BMC Public Heal 2010. Suppl 1 (10):1471-2458.

[13] Saloua A. The International Health Regulations (2005) and border health control in Morocco. Brief, July 2008. 108p.

[14] Ministry of Health and the Fight against AIDS (MSLS). Ivory Coast. National Authority of Civil Aviation (ANAC). Procedural Manual for the Prevention of the Spread of Communicable Diseases by Air Travelers at Félix HOUPHOUET-BOIGNY International Airport.: 1-16.

[15] Ministry of Health and the Fight against AIDS (MSLS). Ivory Coast. Activity report: Second phase of the yellow fever vaccination prevention campaign in 33 health districts of Côte d'Ivoire. 07 to December 16, 2012. 29p.

[16] World Health Organization. Strengthening national capacity for epidemic preparedness and response to implement the IHR (2005) at the national level. WHO / CDS / EPR / LYO / 2006. 4: 1-60. Masanza MM, et al. Laboratory capacity building for the International Health Regulations (IHR [2005]) in resourcepoor countries: the experience of the African Field Epidemiology Network (AFENET). BMC Public Heal 2010. 10 (Suppl 1):S8.

[17] World Health Organization (WHO). Pan American Organization. Issues and implementation of the International Health Regulations in the Caribbean. InVS Martin December 2008. 1-10.

[18] World Health Organization (WHO). Weekly Epidemiological Record (REH). Weekly Epidemiological Record (REH). August 8, 2008. 83 (32): 285-292.

[19] Bakari1 and Gasto Frumence. Challenges to the implementation of International Health.

[20] Regulations (2005) on Preventing Infectious Diseases: experience from Julius Nyerere International Airport Tanzania, Glob Health Action 2013, 6: 20942.

[21] Gostin L. O. and KATZ R. The International Health Regulations: The Governing Framework for Global Health Security. The Milbank Quarterly, Vol. 94, No. 2, 2016 (pp. 264-313). 
[22] Liu B, Sun Y, Dong Q, Zhang Z, Zhang L. Strengthening core public health capacity based on the implementation of the International Health Regulations (IHR) (2005): Chinese lessons. Int $J$ Health Policy Manag 2015; 4: 381-386. doi: 10.15171/ijhpm.2015.84.
[23] Hsiao-Hsuan Chiu et al. Building core capacities at the designated points of entry according to the International Health Regulations 2005: a review of the progress and prospects in Taiwan, Glob Health Action 2014, 7: 24516. 